\title{
Adaptation to different noninvasive ventilation masks in critically ill patients*
}

\author{
Adaptação a diferentes interfaces de ventilação \\ mecânica não invasiva em pacientes críticos
}

\section{Renata Matos da Silva, Karina Tavares Timenetsky, Renata Cristina Miranda Neves, Liane Hirano Shigemichi, Sandra Sayuri Kanda, Carla Maekawa, Eliezer Silva, Raquel Afonso Caserta Eid}

\begin{abstract}
Objective: To identify which noninvasive ventilation (NIV) masks are most commonly used and the problems related to the adaptation to such masks in critically ill patients admitted to a hospital in the city of São Paulo, Brazil. Methods: An observational study involving patients $\geq 18$ years of age admitted to intensive care units and submitted to NIV. The reason for NIV use, type of mask, NIV regimen, adaptation to the mask, and reasons for non-adaptation to the mask were investigated. Results: We evaluated 245 patients, with a median age of 82 years. Acute respiratory failure was the most common reason for NIV use (in 71.3\%). Total face masks were the most commonly used (in 74.7\%), followed by full face masks and near-total face masks (in 24.5\% and $0.8 \%$, respectively). Intermittent NIV was used in $82.4 \%$ of the patients. Adequate adaptation to the mask was found in 76\% of the patients. Masks had to be replaced by another type of mask in 24\% of the patients. Adequate adaptation to total face masks and full face masks was found in $75.5 \%$ and $80.0 \%$ of the patients, respectively. Non-adaptation occurred in the 2 patients using near-total facial masks. The most common reason for non-adaptation was the shape of the face, in 30.5\% of the patients. Conclusions: In our sample, acute respiratory failure was the most common reason for NIV use, and total face masks were the most commonly used. The most common reason for non-adaptation to the mask was the shape of the face, which was resolved by changing the type of mask employed.
\end{abstract}

Keywords: Intermittent positive-pressure ventilation; Masks; Respiratory insufficiency.

\section{Resumo}

Objetivo: Identificar as interfaces de ventilação não invasiva (VNI) mais utilizadas e os eventuais problemas relacionados a sua adaptação em pacientes críticos internados em um hospital na cidade de São Paulo, SP. Métodos: Estudo observacional, com pacientes acima de 18 anos admitidos nas unidades de pacientes graves que usaram VNI. Foram coletados a causa de uso da VNI, interface utilizada, esquema de uso da VN1, adaptação e motivos para a falta de adaptação à interface. Resultados: Avaliamos 245 pacientes, com média de idade de 82 anos. A insuficiência respiratória aguda foi a causa mais frequente de uso da VNI $(71,3 \%)$. A interface mais utilizada foi a máscara facial total $(74,7 \%)$, seguida por máscara facial e máscara facial quase total $(24,5 \%$ e $0,8 \%$, respectivamente). Em $82,4 \%$ dos pacientes, a VNI foi utilizada por periodos. A adaptação adequada à interface ocorreu em $76 \%$ dos pacientes. As máscaras tiveram de ser trocadas em $24 \%$ dos pacientes. Houve adaptação adequada à máscara facial total e à máscara facial em 75,5\% e em 80,0\% dos pacientes, respectivamente. A adaptação foi inadequada nos 2 pacientes que utilizaram a máscara facial quase total. A causa mais frequente da falta de adaptação foi o formato da face, em 30,5\% dos pacientes. Conclusões: Nesta amostra, a insuficiência respiratória aguda foi a causa mais frequente de uso da VNl, e a máscara facial total foi a interface mais utilizada. A causa mais comum da falta de adaptação à máscara foi o formato da face, que foi resolvida após a troca da interface.

Descritores: Ventilação com pressão positiva intermitente; Máscaras; Insuficiência respiratória.

\footnotetext{
* Study carried out in the Department of Intensive Care - Critically IIl Patients, Hospital Israelita Albert Einstein, São Paulo, Brazil. Correspondence to: Renata Matos da Silva. Hospital lsraelita Albert Einstein, Unidade Morumbi, Departamento de Fisioterapia de Pacientes Graves, Avenida Albert Einstein, 627/701, 5º andar, Bloco B, CEP 05651-901, São Paulo, SP, Brasil.

Tel. 5511 99459-3581. Fax: 5511 2151-9411. E-mail: renatams@einstein.br

Financial support: None.

Submitted: 28 September 2012. Accepted, after review: 5 April 2013.
} 


\section{Introduction}

Acute respiratory failure (ARF) causes severe deterioration of gas exchange, which can result in the need for ventilatory support via orotracheal intubation (OTI). Ventilatory support via OTl is associated with a high risk of complications, such as tracheal stenosis and pneumonia. In contrast, noninvasive ventilation (NIV) has proven to be an effective modality in the treatment of respiratory failure of various causes. The use of NIV for the treatment of patients with ARF or chronic respiratory failure has certainly been one of the greatest advances in mechanical ventilation in recent decades. ${ }^{(1-3)}$

A safe and effective method in correcting the pathophysiological mechanisms of ARF, NIV reduces the work of breathing and improves oxygenation while simultaneous treatments address the causes of ARF. ${ }^{(4,5)}$ In some patients, however, NIV has limited effectiveness because of non-adaptation to the masks, significant air leaks, feelings of claustrophobia, aerophagy, and presence or risk of facial injuries. ${ }^{(6)}$ In addition, the time spent by nurses and therapists on frequent mask adjustments, with the objective of preventing excessive leaks and providing adequate monitoring, generates an additional workload for the team. ${ }^{(7)}$

An effective NIV program must pay attention to detail, such as provision of training in NIV monitoring for caregivers and professionals, selection of an appropriate ventilatory strategy for each condition, and use of an appropriate mask for each patient. ${ }^{(7)}$

Few studies have compared the effectiveness of different types of masks in NIV. In addition, the appropriate mask for use in NIV has yet to be defined..$^{(8,9)}$

A recent study evaluated the use of three different masks-nasal masks, face masks, total face masks (TFMs)-by using an analog scale with questions related to comfort. In terms of leaks and nasal pain, TFMs showed better performance; however, there was a higher incidence of feelings of claustrophobia. It is of note that the study involved healthy individuals, which does not allow a full extrapolation of the results to patients whose clinical situation could also affect the adaptation to the masks. ${ }^{(10)}$

Another study examined the physiological effects of different masks in patients with either hypoxemic or hypercapnic ARF. Four different masks (two types of face masks, one type of TFM, and a mouthpiece) were considered, and patient respiratory effort during the use of each mask was evaluated on the basis of the dead space in each one. Although the researchers concluded that there were no major differences between the masks in terms of the work of breathing, they did not evaluate patient adaptation to the masks; rather, they evaluated patient respiratory effort. In addition, the masks used in that study are different from those used in our institution. ${ }^{(11)}$

Nasal and oronasal masks are the ones most commonly used for application of NIV in the hospital environment. In an attempt to improve patient comfort with and tolerance of NIV, new masks have become available in recent years, among which are TFMs, also known as "full face masks".(1)

Because of their greater contact area with the face of the patient, TFMs have the advantage of minimizing air leak and allowing the use of higher inspiratory pressures, as well as minimizing skin injury associated with prolonged use of NIV, making it more comfortable for the patient to use them. ${ }^{(1)}$

In our institution, during patient care, we observed a considerable reduction in the rates of complications related to the use of TFMs, these being the masks of choice by the staff of the institution and also being the preferred masks by patients, with exceptions in case of intolerance or better adaptation to another type of mask, because many patients already received NIV at home and chose to use the same type of device.

In a pilot study conducted in the units for critically ill patients in our institution, we observed that even TFMs caused adaptation problems, making it necessary to replace them by another type of mask in order to achieve better adaptation and, consequently, allow patients to take full advantage of NIV. A relevant finding in that pilot study was the fact that there was greater NIV mask use compliance in the ICU than in semi-intensive care departments, such as the coronary care unit and the semi-intensive care unit, although the level of interference of the clinical status of the patient with this adaptation was not determined.

In this context, we collected information about the use of NIV masks in our institution in order to identify the main types of patientventilator interface used by our patients, as well 
as the problems related to the adaptation to such masks, on the basis of the views of the therapists who were responsible for monitoring patients and adapting them to their masks.

\section{Methods}

After the study design had been approved by the local ethics committee, all patients 18 years of age or older who received NIV in the ICUs, coronary care unit, or semi-intensive unit of the Hospital Israelita Albert Einstein, located in the city of São Paulo, Brazil, between August of 2009 and July of 2011, were included in the study.

Data were obtained by using a data collection form with specific questions, which were answered by the therapists who were responsible for monitoring patients and adapting them to their masks. Patients were not asked any questions, and this was an observational study, in which only those involved in the investigation were aware of its objectives. Therefore, for the physical therapists who were responsible for the direct care of patients, this was a blind study.

A data collection form was filled out for each patient; however, the patients for whom NIV use was discontinued and, after some time, resumed were included again, since their clinical status was different. In addition, if a given patient did not adapt to a given mask and this mask was replaced by another type of mask, the same criteria were reevaluated.

The data collection form addressed the following items: patient age; reason for NIV use; type of mask; NIV regimen (continuous, intermittent, or nocturnal-only use); adaptation to the mask (adequate or inadequate); complications; and need to replace the mask by another type of mask.

The data obtained were entered into and analyzed by using Excel spreadsheets, and all printed documents were filed in a folder specific to the study.

Initially, with the objective of identifying the main types of masks used and the problems related to the adaptation to such masks, we conducted a descriptive exploratory analysis of all observed variables. Qualitative variables are expressed as absolute and relative frequencies. Quantitative variables are expressed as mean and standard deviation (normal distribution) or as median and range (non-normal distribution).
In order to investigate the relationship between the variables age, reason for NIV use, type of mask, NIV regimen, and adaptation to the mask, we generated scatterplots and calculated Pearson correlation coefficients, for variables with normal distribution, and Spearman's correlation coefficients, for variables with non-normal distribution.

In order to study the influence of age, reason for NIV use, and NIV regimen on the likelihood of adequate adaptation to the masks, we adjusted these variables by using a multiple logistic regression model. All variables with a descriptive level of less than 0.20 in the univariate approach were included in the initial model.

The level of significance was set at 0.05. The statistical program used was the Statistical Package for the Social Sciences, version 16.0 (SPSS Inc., Chicago, IL, USA).

\section{Results}

We evaluated 245 patients, with a median age of 82 years (range, 20-107 years; Table 1).

The most common reason for NIV use was a diagnosis of ARF (in 71.3\%), followed by a need for exercise or lung expansion (in 10.2\%), use after weaning from invasive mechanical ventilation (in 6.1\%), and obstructive sleep apnea (in 8.6\%), as shown in Table 1.

The most commonly used masks were TFMs (Philips Respironics, Murrysville, PA, USA), in 74.7\%; followed by face masks (Comfo mask; HSINER Co. LTD., Taichung, Taiwan-Mirage; ResMed Corp., San Diego, CA, USA-and Comfort full; Philips Respironics), in 24.5\%; and by neartotal face masks (PerforMax; Philips Respironics), in $0.8 \%$ (Figure 1 ).

Regarding the NIV regimen, intermittent NIV was the most commonly used (in 82.4\%), followed by continuous NIV (in 10.6\%) and nocturnalonly NIV (in 6.9\%; Table 2).

Adequate adaptation to the mask was found in $76 \%$ of the patients (Figure 1). Non-adaptation to the mask (in 24\%) caused the type of mask to be changed until adequate adaptation was achieved.

Adequate adaptation to TFMs was found in $75.5 \%$ of the patients, whereas adequate adaptation to face masks was found in $80.0 \%$ of the patients. Adequate adaptation to neartotal face masks did not occur, perhaps due to 
the fact they were seldom used, in only two patients (Figure 1).

We found that the shape of the face, especially the nose contour, was the most common reason for non-adaptation, in 30.5\% of the cases; followed by patient-reported discomfort, in $28.8 \%$; air leaks around the mask, in 27;7\%; feelings of claustrophobia, in 18.6\%; patient non-cooperation, in $10.1 \%$; patient agitation, in 6.7\%; facial trauma or injury, in 1.7\%; type of fixation device or "halter", in 1.7\%; and other reasons, in $1.7 \%$ (Table 2 ).

\section{Discussion}

The use of NIV for the control and treatment of ARF or chronic respiratory failure has certainly

Table 1 - Characteristics of the 245 patients evaluated. ${ }^{\text {a }}$

\begin{tabular}{lc}
\hline \multicolumn{1}{c}{ Characteristic } & Result \\
\hline $\begin{array}{l}\text { Age, years }{ }^{\mathrm{b}} \\
\text { Gender }\end{array}$ & $82(20-107)$ \\
$\quad$ Male & $130(53)$ \\
$\quad$ Female & $115(47)$ \\
Reason for noninvasive ventilation use & \\
$\quad$ Acute respiratory failure & $170(69.4)$ \\
$\quad$ Lung expansion & $44(18.0)$ \\
$\quad$ Use after weaning from mechanical & $15(6.1)$ \\
$\quad$ ventilation & \\
$\quad$ Obstructive sleep apnea & $37(15.0)$ \\
\hline
\end{tabular}

${ }^{a}$ Values expressed as $\mathrm{n}(\%)$, except where otherwise indicated.

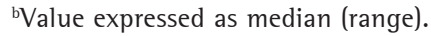

been one of the greatest advances in the care of critically ill patients in recent years.

The use of NIV leads to re-expansion of collapsed areas, improved gas exchange, and reduced work of breathing while simultaneous treatments address the causes of the respiratory failure.

Our study showed that respiratory failure was the main reason for NIV use. However, NIV was also indicated for other purposes, such as lung expansion, being used as a thoracic expansion exercise for short periods during the

Table 2 - Noninvasive ventilation (NIV) regimen and reasons for non-adaptation to the mask.

\begin{tabular}{lc}
\hline \multicolumn{1}{c}{ Variable } & Patients \\
\hline NIV regimen & $202(82.4)$ \\
Intermittent & $26(10.6)$ \\
Continuous & $17(7.0)$ \\
Nocturnal & \\
Reason for non-adaptation & $75(30.5)$ \\
Shape of the face & $70(28.8)$ \\
Discomfort & $68(27.7)$ \\
Leaks & $45(18.6)$ \\
Claustrophobia & $24(10.0)$ \\
Non-cooperation & $16(6.7)$ \\
Agitation & $4(1.7)$ \\
Facial trauma & $4(1.7)$ \\
Type of fixation device & $4(1.7)$ \\
Others &
\end{tabular}

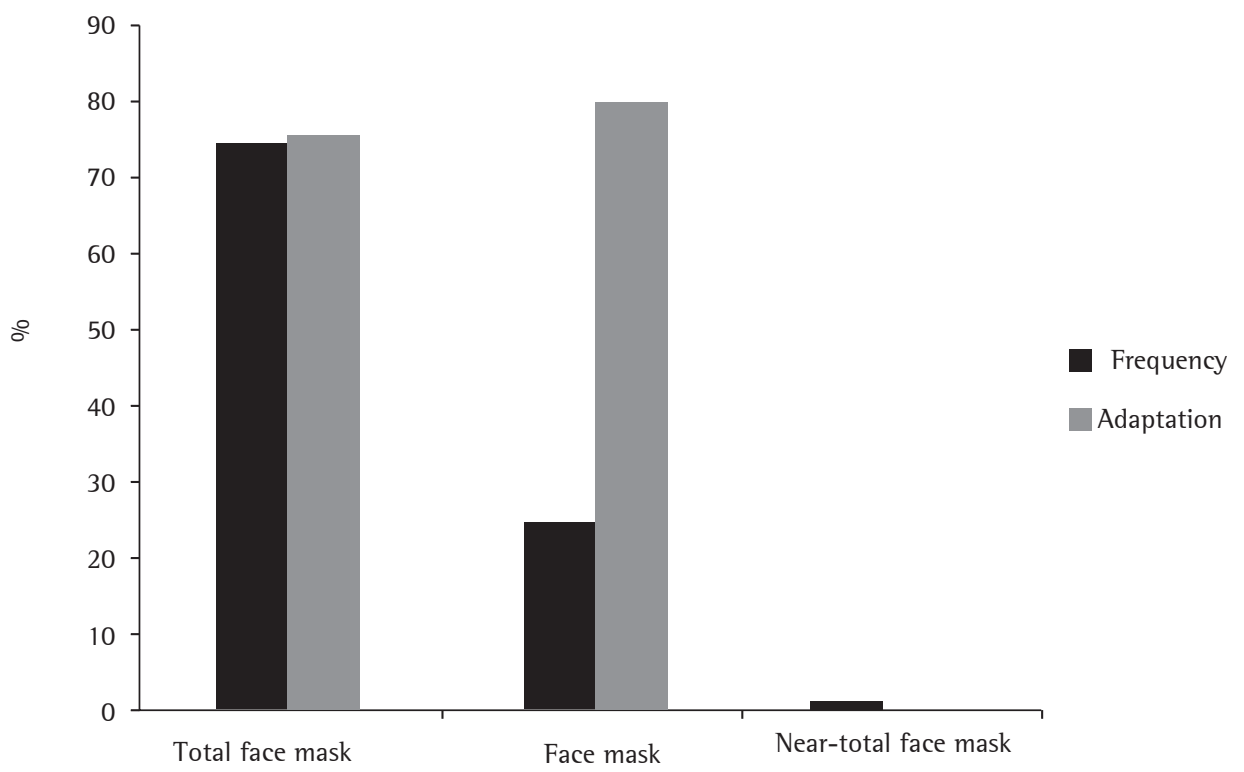

Figure 1 - Frequency of use and adequate adaptation to different masks. 
day and being used in the evening for improving gas exchange or for re-expansion of collapsed lung areas. In addition, in our study, nocturnal use of NIV was mentioned as being indicated to minimize sleep apnea syndrome, as well as being indicated immediately after extubation, acting as an adjuvant in weaning from invasive mechanical ventilation.

It is known that, for each purpose, a NIV regimen is tailored on the basis of its indication and the clinical status of the patient. In our study, intermittent NIV, which consists of use for longer than one-hour periods in the morning, afternoon, and evening, was the most common regimen. The clinical status of the patients who used continuous NIV was more severe, and removal of NIV was allowed only for feeding, oral hygiene, expectoration, and aspiration of secretions. The nocturnal regimen was administered only to patients who had been diagnosed with obstructive sleep apnea and presented with an indication for NIV use.

These findings are important in order to understand the major indications for NIV use and its frequency of use. However, it is of note that an inappropriate choice of the mask or poor adaptation of patients to their masks might affect treatment outcomes. An effective treatment plan using NIV must pay attention to detail, one of which is the use of an appropriate type of mask for each patient. ${ }^{(7)}$

Our study focused on adequate adaptation of patients to their masks, considering their comfort, because adequate adaptation to the mask allows higher compliance with the NIV program proposed, positively contributing to the clinical course.

Mask intolerance can be an important factor in NIV failure, as demonstrated in a study by Conti et al., ${ }^{(12)}$ who compared the efficacy of NIV delivered via a face mask with that of NIV delivered via a helmet in ARF patients after abdominal surgery. Regardless of the type of mask used, oxygenation improved, as did RR, HR, systolic blood pressure, and ventilation parameters. However, the incidence of NIV complications, such as mask intolerance, leaks that compromise ventilation, and ventilator-associated pneumonia, was higher in the group using face masks than in the group using helmets.

In another study, Kwork et al. ${ }^{(13)}$ evaluated tolerance of oronasal and nasal masks in patients with ARF. The success rate tended to be higher with the use of oronasal masks, but without statistical significance. Once again, oxygenation, $\mathrm{RR}$, and HR improved in both groups; however, intolerance of or non-adaptation to the mask was higher in the group using nasal masks.

Chacur et al. ${ }^{(14)}$ compared the use of TFMs with that of traditional face masks in terms of changes in clinical parameters, oxygenation parameters, levels of ventilatory support, and incidence of OTI. The group using TFMs showed better adaptation and therefore tolerated NIV for longer periods than did the group using face masks. In contrast, there were no significant differences in clinical course.

Recent guidelines for the use of NIV mention two randomized controlled studies that compared the use of nose masks with that of orofacial masks, and, although no differences were found in the rates of OTI or mortality, oronasal masks were better tolerated by patients. ${ }^{(15)}$

In our study, adequate adaptation to the mask employed was found in $76 \%$ of the cases. For the patients $(24 \%)$ who did not adapt to the mask of choice, the type of mask was changed until adequate adaptation was achieved. The most commonly used type of mask was TFMs, which is an expected finding, because, in our institution, TFMs have been defined as the mask of choice by the staff on the basis of care observation.

Analyzing adaptation to the types of mask separately, we found adequate adaptation to TFMs in $75.5 \%$ of the cases and adequate adaptation to face masks in $80.0 \%$ of the cases. Therefore, we observed that both types of mask are options that can be used in NIV, and that the acceptance of either one can vary with each patient, depending on their clinical and physical status, or even on their personal preferences.

Considering that the shape of the face was the main reason for non-adaptation, we found that it is difficult to define a type or standard of mask that can fit all anatomical variations. Face masks are available on the market in various types and sizes; however, TFMs are available in a limited range of sizes, which made it difficult for patients with smaller- or larger-than-average faces to adapt to their masks.

We found that some reasons for non-adaptation to the mask, such as respiratory distress, air leaks around the mask, type of fixation device, and facial trauma or injury, were associated with the 
use of a type or size of mask that was inadequate to fit the face of the patient.

In addition, we found that feelings of claustrophobia, patient agitation, and patient non-cooperation because of their personal situation or condition can be resolved, in most cases, by changing the type of mask employed.

In conclusion, it is important to evaluate patient adaptation to their masks in order to ensure an effective NIV compliance program and treatment success. In the present study, ARF was the main reason for NIV use, and TFMs were the most commonly used, with satisfactory patient adaptation, followed by face masks. The main reasons for non-adaptation to NIV were the shape of the face of the patient, patient-reported discomfort with the use of the mask, respiratory distress, and air leaks around the mask. These problems were resolved by changing the type of mask employed.

\section{References}

1. Schettino GP, Reis MA, Galas F, Park M, Franca S, Okamoto V. Ventilação mecânica não invasiva com pressão positiva. J Bras Pneumol. 2007;33(Suppl 2):S92-S105. http://dx.doi.org/10.1590/S1806-37132007000800004 PMid:18026667

2. Organized jointly by the American Thoracic Society, the European Respiratory Society, the European Society of Intensive Care Medicine, and the Société de Réanimation de Langue Française, and approved by ATS Board of Directors, December 2000. International Consensus Conferences in Intensive Care Medicine: noninvasive positive pressure ventilation in acute Respiratory failure. Am J Respir Crit Care Med. 2001;163(1):283-91.http:// dx.doi.org/10.1164/ajrccm.163.1.ats1000 PMid:11208659

3. British Thoracic Society Standards of Care Committee. Non-invasive ventilation in acute respiratory failure. Thorax. 2002;57(3):192-211. http://dx.doi.org/10.1136/ thorax.57.3.192 PMid:11867822 PMCid:1746282

4. Antonelli M, Pennisi MA, Montini L. Clinical review: noninvasive ventilation in the clinical setting--experience from the past 10 years. Crit Care. 2005;9(1):98-103. http://dx.doi.org/10.1186/cc2933 PMid:15693991 PMCid: 1065090

5. Caples SM, Gay PB. Noninvasive positive pressure ventilation in the intensive care unit: a concise review. Crit Care
Med. 2005;33(11):2651-8. http://dx.doi.org/10.1097/01. CCM.0000186768.61570.69

6. Criner GJ, Travaline JM, Brennan KJ, Kreimer DT. Efficacy of a new full face mask for noninvasive positive pressure ventilation. Chest. 1994;106(4):1109-15. http://dx.doi. org/10.1378/chest.106.4.1109 PMid:7924481

7. Kacmarek RM. Noninvasive positive pressure ventilation: the little things do make the difference! Respir Care. 2003;48(10):919-21.PMid:14525627

8. Willson GN, Piper AJ, Norman M, Chaseling WG, Milross MA, Collins ER, et al. Nasal versus full face mask for noninvasive ventilation in chronic respiratory failure. Eur Respir J. 2004;23(4):605-9. http://dx.doi.org/10.1 183/09031936.04.00051604 PMid:15083762

9. Navalesi P, Fanfulla F, Frigerio P, Gregoretti C, Nava S. Physiologic evaluation of noninvasive mechanical ventilation delivered with three types of masks in patients with chronic hypercapnic respiratory failure. Crit Care Med. 2000;28(6):1785-90. http://dx.doi.org/10.1097/00003246200006000-00015 PMid:10890620

10. Holanda MA, Reis RC, Winkeler GF, Fortaleza SC, Lima JW, Pereira ED. Influence of total face, facial and nasal masks on short-term adverse effects during noninvasive ventilation. J Bras Pneumol. 2009;35(2):164-73. http:// dx.doi.org/10.1590/S1806-37132009000200010 PMid:19287920

11. Fraticelli AT, Lellouche F, L'her E, Taillé S, Mancebo J, Brochard L. Physiological effects of different interfaces during noninvasive ventilation for acute respiratory failure. Crit Care Med. 2009;37(3):939-45. Erratum in: Crit Care Med. 2009;37(4):1537. http://dx.doi.org/10.1097/ CCM.0b013e31819b575f PMid:19237900

12. Conti G, Cavaliere F, Costa R, Craba A, Catarci S, Festa $\mathrm{V}$, et al. Noninvasive positive-pressure ventilation with different interfaces in patients with respiratory failure after abdominal surgery: a matched-control study. Respir Care. 2007;52(11):1463-71. PMid:17971249

13. Kwok H, McCormack J, Cece R, Houtchens J, Hill NS. Controlled trial of oronasal versus nasal mask ventilation in the treatment of acute respiratory failure. Crit Care Med, 2003;31(2):468-73. http://dx.doi.org/10.1097/01. CCM.0000045563.64187.20 PMid:12576953

14. Chacur FH, Vilella Felipe LM, Fernandes CG, Lazzarini LC. The total face mask is more comfortable than the oronasal mask in noninvasive ventilation but is not associated with improved outcome. Respiration. 2011;82(5):426-30. http://dx.doi.org/10.1159/000324441 PMid:21846957

15. Keenan SP, Sinuff T, Burns KE, Muscedere J, Kutsogiannis J, Mehta S, et al. Clinical practice guidelines for the use of noninvasive positive-pressure ventilation and noninvasive continuous positive airway pressure in the acute care setting. CMAJ. 2011;183(3):E195-E214. http://dx.doi.org/10.1503/cmaj.100071 PMid:21324867 PMCid:3042478 


\section{About the authors}

Renata Matos da Silva

Physical Therapist. Hospital Israelita Albert Einstein, São Paulo, Brazil.

\section{Karina Tavares Timenetski}

Physical Therapist. Hospital Israelita Albert Einstein, São Paulo, Brazil.

\section{Renata Cristina Miranda Neves}

Physical Therapist. Hospital Israelita Albert Einstein, São Paulo, Brazil.

Liane Hirano Shigemichi

Physical Therapist. Hospital Israelita Albert Einstein, São Paulo, Brazil.

\section{Sandra Sayuri Kanda}

Physical Therapist. Hospital Israelita Albert Einstein, São Paulo, Brazil.

\section{Carla Maekawa}

Physical Therapist. Hospital Israelita Albert Einstein, São Paulo, Brazil.

\section{Eliezer Silva}

Medical Manager in Intensive Care. Hospital lsraelita Albert Einstein, São Paulo, Brazil.

\section{Raquel Afonso Caserta Eid}

Coordinator of Physical Therapy. Hospital Israelita Albert Einstein, São Paulo, Brazil. 